\title{
Comparison of eri and tasar silk fibroin scaffolds for biomedical applications
}

\author{
Muthumanickkam Andiappan ${ }^{1} \cdot$ Tinesh Kumari $^{1} \cdot$ Subramanian Sundaramoorthy $^{1}$. \\ Gowri Meiyazhagan $^{2} \cdot$ Prasath Manoharan $^{2} \cdot$ Ganesh Venkataraman $^{2}$
}

Received: 14 August 2015/ Accepted: 19 February 2016/Published online: 8 March 2016

(C) The Author(s) 2016. This article is published with open access at Springerlink.com

\begin{abstract}
The cultivated silk, mulberry, is being used as biomaterial in different forms. Eri, tasar and muga are some of the known wild silk varieties. The studies on biomedical applications of electrospun mats produced from these wild silks are limited though few studies on eri silk are available. In this work, comparison was made between eri and tasar silk fibroin scaffolds for biomedical application. The scaffolds were produced from eri silk fibroin (ESF) and tasar silk fibroin (TSF) by electrospinning method and they were treated with ethanol to improve dimensional stability. Ethanol treatment increased the crystallinity\% of both ESF and TSF scaffolds. The crystallinity percentage of the ESF and TSF scaffolds was found to be 46.7 and $42.8 \%$ respectively. Thermal stability was higher for ESF than that of TSF scaffold. The hemolytic \% of ESF and TSF scaffolds was found to be 1.3 and $7.7 \%$ respectively. The platelet adhesion on the surface of ESF scaffold was lower than that found on TSF scaffold. Better fibroblast cell attachment, binding and spreading was found on the ESF scaffold. The cell viability on ESF scaffold was $83.78 \%$ and in TSF was $78.01 \%$ for $48 \mathrm{~h}$. The results showed that ESF electrospun scaffold can be considered as a better biomaterial for biomedical applications compared to that of TSF scaffold.
\end{abstract}

Keywords Biomedical · Blood compatibility - Eri silk fibroin · Protein - Sterilization - Tasar silk fibroin - Tissue cell culture

Subramanian Sundaramoorthy

ssresgroup12@gmail.com; ssubbu.anna@gmail.com

1 Department of Textile Technology, Anna University, Chennai, India

2 Sri Ramachandra Medical University, Chennai, India

\section{Introduction}

Silk is identified as one of the important biomaterial due to its biocompatibility, biodegradability and presence of natural proteinthough it is largely consumed for clothing applications. It is being used as suture material because of its higher tensile strengthand bio-resorbable properties. Silk can be extracted and decomposed easily by nature (Mei-po Ho et al. 2012). Silk consists of two components, fibroin $(80 \%)$ and sericin $(20 \%)$. Fibroin is a water insoluble protein with highly oriented crystalline structure and sericin is a gummy substance which is removed during degumming process; it is one of cause for inducing inflammatory reaction (Meinel et al. 2003; Santin et al. 1999). Silk is characterized by a highly repetitive primary sequence that leads to significant homogeneity in secondary structure, i.e., triple helices B-sheets. These types of proteins usually exhibit impressive mechanical properties and hence provide an important set of material options in the field of controlled release and scaffolds for tissue engineering (Altman et al. 2003).

Silk is broadly classified as wild silk (Eri, Tasar, Muga) and domestic silk (mulberry). In the mulberry silk (Bombyxmori), glycine, alanine and serine constitute about $82 \%$ of the amino acids, whereas, it is $73 \%$ in the nonmulberry silks with a high proportion of alanine. The hydrophilic to hydrophobic amino acid ratio for non-mulberry silks (9.06-9.85) is higher compared to that of the mulberry varieties (5.29-6.22), which results in higher moisture content of non-mulberry silks (Altman et al. 2003; Sen and Murugesh Babu 2003). Silk fibroin has RGD (arginine-glycine-aspartic acid) sequence, which enhances cell adhesion, cell proliferation and differentiation (Muthumanickkam et al. 2013b; Bray et al. 2013). Silk I is the helical protein present in the silk glands prior 
to spinning. When the silk fibroin is treated with ethanol, the water soluble silkI undergoes structural change to water insoluble silkII protein, which is also an effective sterilization approach to silk fibroin scaffolds (Zhang et al. 2012). Eri silk fibroin (ESF) is composed of about 100 repetitions of alternating polyalanine $\left(\mathrm{Ala}^{12-13}\right)$ and glycine-rich domains (Nakazawa et al. 2003). The glycine motifs are basically present in the random coil state structure, and it provides flexibility to the silk fibre, whereas the alanine rich motifs support to form crystalline B-sheet structure. The sum of Gly and Ala residues in Eri silk is $82 \%$ (Nakazawa et al. 2003; Huemmerich et al. 2006). The presence of sericin in Eri silk (Samiacynthiaricini) is less than that of mulberry silk, and also possesses higher amount of moisture regain than mulberry silk. ESF has higher content of hydrophilic and positively charged amino acids, which enhances the cell attachment and proliferation on the scaffold (Sen and MurugeshBabu 2004; Min et al. 2004).

The scaffolds fabricated from tropical Tasar (A. Mylitta) silk fibroin (TSF) has higher compressive strength over those made from other naturally derived materials such as collagen and chitosan (Mei-po Ho et al. 2012). The presence of the tripeptide sequence of ArgGly-Asp (RGD) in TSF acts as a biological recognition signal to promote cell adhesion, and consequently make TSF suitable for biomedical applications (Min et al. 2004). The higher alanine content in Tasar silk favors a distinct crystalline morphology; larger crystallites and lower crystallinity in non-mulberry varieties yield higher elongation \%. Tasar shows the highest moisture regain value $(10.76 \%)$, followed by eri $(10.21 \%)$ and muga $(9.82 \%)$ for the outer layers. The higher moisture regain of non-mulberry silks suggests that all three non-mulberry silk varieties may consist of a higher ratio of hydrophilic to hydrophobic amino acid residues in their chemical architecture. Studies on application of mulberry silk for biomedical applications and comparison of eri and mulberry silk have been carried out by Muthumanickkam et al. (2013b). In the present work, a comparison was made between Eri silk (Samiacynthia ricini) and Tasar silk (A. mylitta) fibroin scaffolds. The scaffolds were produced by electrospinning method and subsequently treated with ethanol to improve dimensional stability. The physical and chemical characterization was carried out using Scanning electronic microscope (SEM), Thermogravimetric analyzer (TGA), FTIR spectrometer and X-ray diffractometer (XRD). The blood compatibility and platelet adhesion on the scaffold surface was examined. The fibroblast cells were used to evaluate the cell attachment and cell viability on the silk fibroin scaffolds.

\section{Materials and methods}

\section{Preparation of scaffolds}

Eri and Tasar silks were degummed using $0.5 \mathrm{M}$ sodium carbonate and $1 \mathrm{~g}$ per litre of soap solution boiling at $95{ }^{\circ} \mathrm{C}$ under the $\mathrm{pH}$ range of 7.5-8.0 for removing sericin. The degummed silk (silk fibroin) was dissolved in Trifluroacetic acid $(99.9 \%)$ to prepare polymer solution. The fibroin solution was taken in a $2 \mathrm{ml}$ syringe with the needle of inner diameter $1.3 \mathrm{~mm}$ and it was fixed on a infusion pump held in vertical position. The optimized concentration of $15 \%$ (w/v) was maintained for Eri as well as Tasar fibroin solutions for producing nanofibrous scaffolds without any beads or spraying. The distance between the needle and the drum collector was kept at $15 \mathrm{~cm}$, a $20 \mathrm{kV}$ voltage was applied and the flow rate was set at $0.6 \mathrm{ml} / \mathrm{h}$. In order to improve the dimensional stability, the scaffolds were immersed in ethanol for $1 \mathrm{~h}$, which also sterilizes the material (Muthumanickkam et al. 2013b).

\section{Physical characterization of scaffolds}

The eri and tasar silks were taken in various forms, viz., un-degummed silk, degummed silk, electrospun scaffolds without ethanol treatment and scaffolds with ethanol treatment. FTIR spectrometer (Perkin Elmer USA, PE $1600)$ in the region of $4000-500 \mathrm{~cm}^{-1}$ with $4 \mathrm{~cm}^{-1}$ resolution was used to analyze the change in functional groups in the above forms of silks. Scanning was carried out at a speed of $0.04 \mathrm{deg} / \mathrm{s}$ with a measurement range of $1^{\circ}-70^{\circ}$. The area of scattering was measured using Fityk software. The X-ray diffract meter (Bruker USA, D8) with CuK- $\alpha$ radiation $\left(\lambda=1.54 \mathrm{~A}^{\circ}\right)$ was used to determine the crystallite size and percentage of crystallinity of eri silk and tasar silk scaffolds; they were calculated using the Eqs. (1) and (2).

Crystallite size $\left(\mathrm{A}^{\circ}\right)=\frac{K \lambda}{\beta \operatorname{Cos} \theta}$

Here, $k$ is the shape factor, $\lambda=1.54 \mathrm{~A}^{\circ}$.

Crystallinity (\%)

$$
=\frac{\text { Total area of crystalline peak }}{\text { Total area of crystalline and amorphous region }} \times 100
$$

The thermal stability of the scaffolds was analyzed using the TGA (TA Instruments, Q500) at temperatures ranging from 37 to $700{ }^{\circ} \mathrm{C}$ in a nitrogen atmosphere at a heating rate of $20^{\circ} \mathrm{C} / \mathrm{min}$.

The scaffold has to withstand the stress during cell culture and hence the tensile property of scaffold was 
tested under standard atmospheric condition using a Universal (Instron 3369) strength tester. The scaffold was cut into specimen of size $10 \times 50 \mathrm{~mm}$. The thickness of both the Eri silk and Tassar silk scaffolds was maintained at $0.16 \mathrm{~mm}$. Glue tapes were fixed at the top and bottom of the scaffold and then it was clamped on the jaw of the tester; the gauge length was maintained at $30 \mathrm{~mm}$ and the test speed was kept at $20 \mathrm{~mm} / \mathrm{min}$.

Porosity is an important characteristic which would influence the tissue attachment and growth. The porosity of the scaffolds was measured by using a porosimeter based on capillary flow method. Scaffolds were cut into $5 \times 5 \times 1 \mathrm{~mm}$ pieces and the samples were impregnated with the wetting liquid. An inert gas $\mathrm{N}_{2}$ was used to displace this wetting liquid from the porous network. The pressure required to empty a pore corresponds to the pressure necessary to evacuate the liquid from the most constricted part of it. The Young-Laplace formula permits calculating of pore diameter from the measured pressure (Nazarov et al. 2004).

The water uptake of scaffold was measured as per the following method: Nanofibrous scaffold was dried in an oven at $60{ }^{\circ} \mathrm{C}$ under vacuum for overnight and the dry weight of scaffolds $\left(W_{\mathrm{d}}\right)$ was measured. The scaffolds were immersed in distilled water at room temperature for $24 \mathrm{~h}$. Then the excess water on the scaffold was removed using white tissue paper by applying uniform pressure, and the wet weight of the scaffolds $\left(W_{\mathrm{s}}\right)$ was determined. The water uptake of scaffold was calculated using the Eq. 3.

Water uptake $(\%)=\frac{W_{\mathrm{s}}-W_{\mathrm{d}}}{W_{\mathrm{d}}} \times 100$

\section{Biological characterization}

\section{Hemolytic test}

Blood compatibility of both ESF and TSF scaffolds was analyzed using hemolytic test. Human blood collected from a healthy volunteer in a $3.8 \%$ sodium citrate coated tube was diluted with phosphate buffer saline (PBS) (pH 7.4) in the ratio of 1:20 (v/v). The blood diluted with PBS was taken as a negative control, and the blood with Triton $\mathrm{X}$ was taken as a positive control. The ESF and TSF scaffolds were treated with ethanol and then autoclaved. The scaffolds were immersed in $100 \mu \mathrm{L}$ of blood and PBS solution followed by incubation at $37{ }^{\circ} \mathrm{C}$ for $60 \mathrm{~min}$. Then, the samples were spun at $3000 \mathrm{rpm}$ for $10 \mathrm{~min}$. The optical density value (OD) of the supernatant was measured at $545 \mathrm{~nm}$ using spectrophotometer and the hemolytic rate was calculated using Eq. 4.

$$
\begin{aligned}
& \text { Hemolytic }(\%) \\
& =\frac{\text { OD value of sample }- \text { OD value of negative }}{\text { OD value of positive }- \text { OD value of negative }} \times 100
\end{aligned}
$$

Platelet adhesion test was conducted to analyse the behavior of silk fibroin scaffolds while interacting with the human platelets. For this study, $5 \mathrm{~mL}$ of fresh human blood was collected from a healthy volunteer. The fresh blood was treated with $3.8 \%$ sodium citrate, and spun at $3000 \mathrm{rpm}$ for $10 \mathrm{~min}$ at $4{ }^{\circ} \mathrm{C}$ to obtain platelet-rich plasma (PRP). The platelet was placed on the scaffold and kept under incubation for $1 \mathrm{~h}$. The platelet-attached ESF and TSF scaffolds were washed twice with PBS, and then immersed in PBS containing $2.5 \%$ glutaraldehyde $(\mathrm{pH}$ 7.4) for overnight. They were subsequently dehydrated in gradient ethanol $(20,40,60,80$, and $100 \%)$ for $15 \mathrm{~min}$ and then dried in vacuum. The morphology of the platelets adhered on the scaffolds was characterized using SEM.

\section{Cell culture}

The scaffolds were treated with ethanol immediately after the removal of scaffold from the electrospinning machine to avoid curling and then it was autoclaved before the biological characterization. Rat L6 muscle fibroblasts were seeded at a density of $1 \times 10^{4}$ cells per silk fibroin scaffold. The cells were incubated at $37{ }^{\circ} \mathrm{C}$ with $5 \% \mathrm{CO}_{2}$ for a period of 24 and $48 \mathrm{~h}$. After the incubation, the scaffolds were removed from the well and rinsed with PBS twice to remove non-adhered cells from the scaffold. Then the scaffolds were fixed with $2.5 \%$ phosphate-buffered glutaraldehyde and kept at $4{ }^{\circ} \mathrm{C}$ for $2 \mathrm{~h}$ and subsequently dehydrated with gradient ethanol solution $(20,40,60,80$, and $100 \%)$. The dried scaffolds were sputtered with iron and observed by SEM.

\section{MTT assay}

Rat L6 muscle fibroblasts were seeded at a density of $1 \times 10^{4}$ per 96 well plates. After confluence, the scaffolds were placed on cells of the well plate. The cells treated with Triton X-100 were used as the positive control. After the requisite incubation time, $5 \mu \mathrm{L}$ of MTT reagent $(10 \mathrm{mg} / \mathrm{mL})$ was added to the medium and incubated for $4 \mathrm{~h}$ at $37{ }^{\circ} \mathrm{C}$, $95 \%$ RH in an incubator containing $5 \% \mathrm{CO}_{2}$. Subsequently, the medium was discarded and $200 \mu \mathrm{L}$ of dimethyl sulfoxide (DMSO) was added to record its optical density using spectrophotometer at $540 \mathrm{~nm}$. The optical density value (OD) has varied linearly with the viable cell population. The cell viability percentage was calculated using Eq. 5 . 
Cell viability

$=\frac{(\mathrm{OD} \text { value of sample }(\text { treated well })-\mathrm{OD} \text { value of blank })}{(\mathrm{OD} \text { value of control (untreated well })-\mathrm{OD} \text { value of blank })} \times 100$

The statistical $t$ test was conducted between the samples at $95 \%$ confidence level.

\section{Results and discussion}

\section{Physical characterization of scaffolds}

\section{SEM analysis}

Figure 1a, b respectively show the SEM image and fibre diameter distribution of eri silk and tasar silk fibroin scaffolds without ethanol treatment. From the figures, it can be observed that majority of the fibres in ESF, TSF scaffolds have diameter in the range of 401-500 $\mathrm{nm}$ and 801-1000 $\mathrm{nm}$ respectively. The eri silk fibres have diameter lesser than the tasar fibres due to difference in molecular weight of fibroins of eri and tasar silks. The molecular weight of fibroin is associated with cystine content in the silk. The TSF has higher cystine content than ESF (Sen and MurugeshBabu 2004).

\section{Thermal stability}

The thermogravimetric curves of ethanol untreated ESF and TSF scaffolds are shown in Fig. 2a, b respectively. The initial weight loss of the scaffolds occurs at around $100{ }^{\circ} \mathrm{C}$ due to the evaporation of water from the silk fibroin scaffolds. The second weight loss takes place at 380 and $350{ }^{\circ} \mathrm{C}$ respectively for eri silk and tasar silk.

The thermograms of ethanol treated ESF and TSF scaffolds are shown in Fig. 3a, b respectively. The initial weight loss of ethanol treated silk fibroin scaffolds occurs
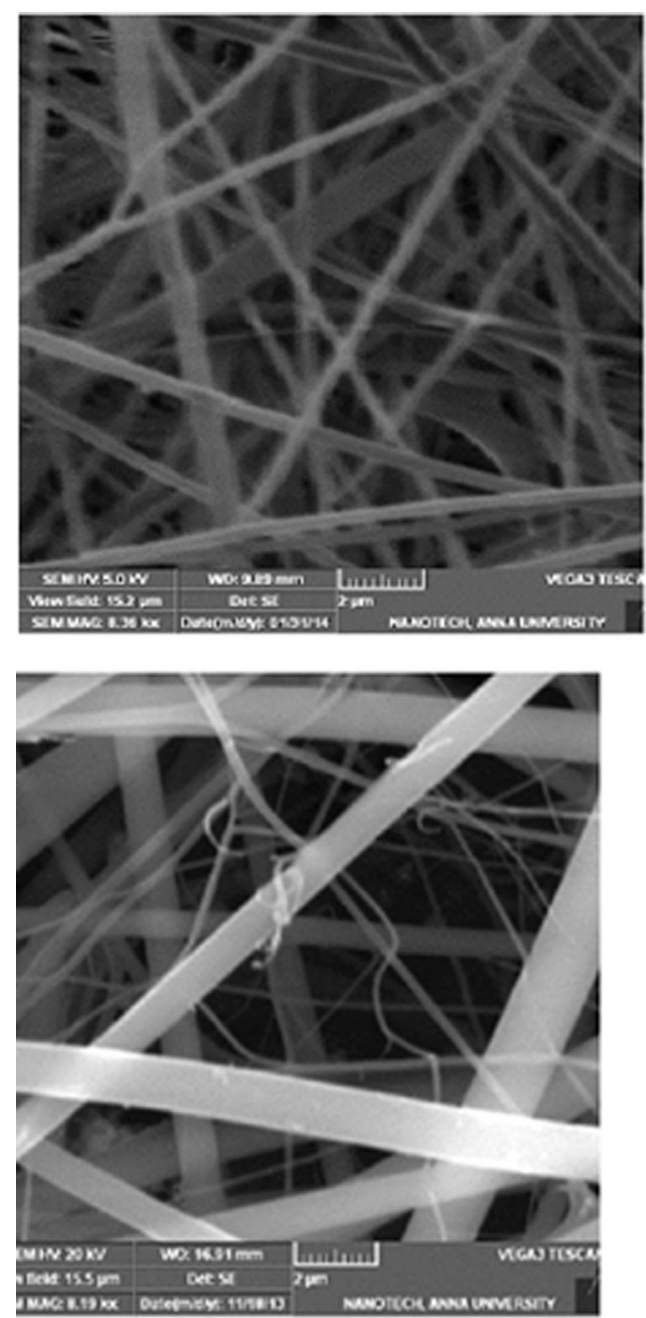

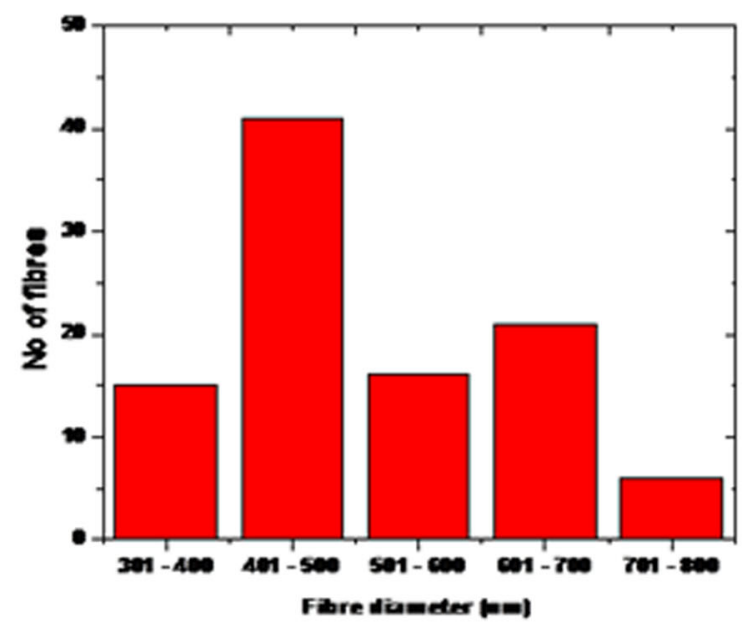

(a)

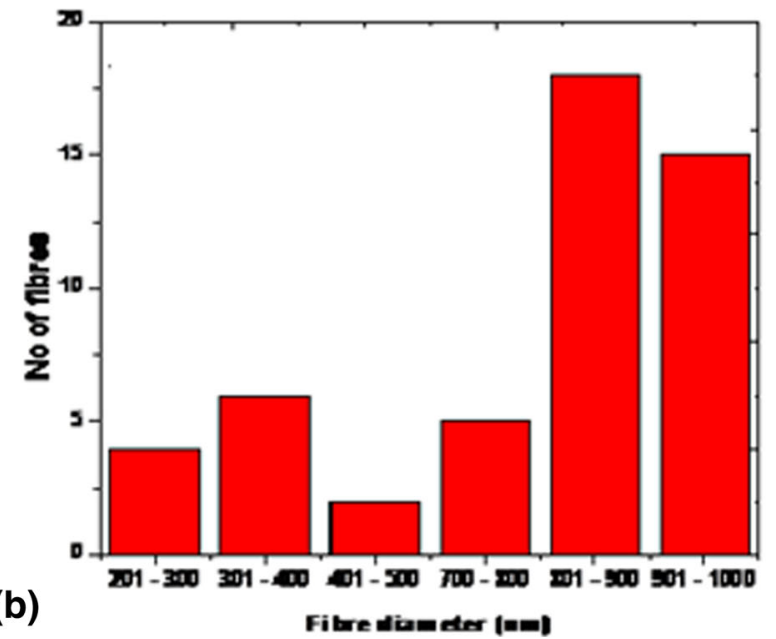

Fig. 1 SEM image and histogram of a ESF and $\mathbf{b}$ TSF scaffolds 


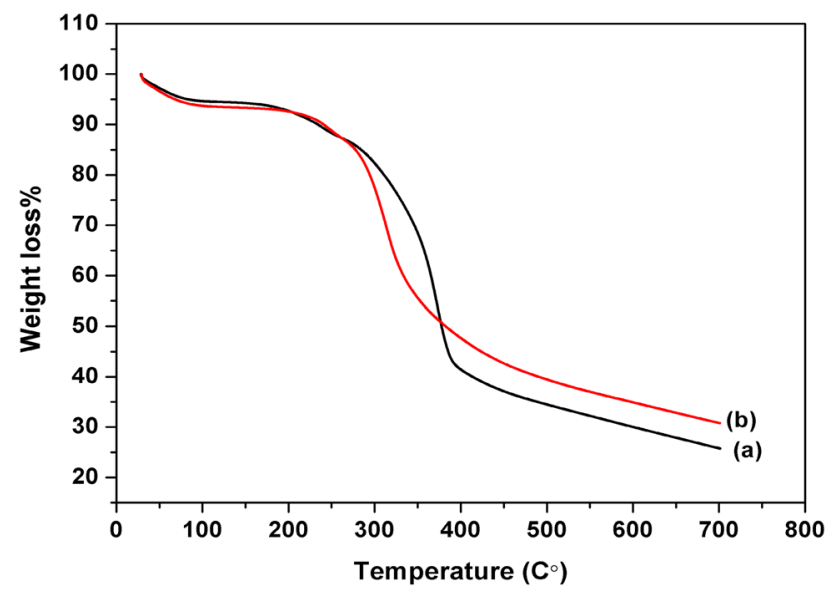

Fig. 2 Thermogram of ethanol untreated $a$ ESF and $b$ TSF scaffolds

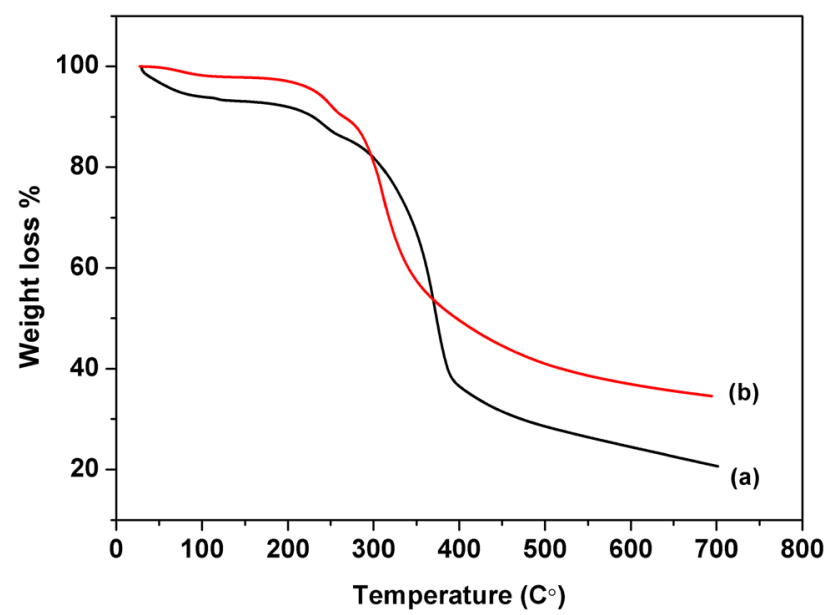

Fig. 3 Thermogram of ethanol treated $a$ ESF and $b$ TSF scaffolds

at around $100{ }^{\circ} \mathrm{C}$ due to the evaporation of water from the silk fibroin scaffolds. The second weight loss takes place at 390 and $370{ }^{\circ} \mathrm{C}$ and respectively for ESF and TSF scaffolds. The second weight loss of silk is due to breakdown of the side chain of amino group's residuals as well as the cleavage of the peptide bond (Muthumanickkam et al. 2013b). The result shows that ESF scaffold has marginally better thermal stability than the TSF scaffolds in ethanol treated as well as untreated conditions.

\section{FTIR analysis}

Figure 4a and brespectively shows the FTIR spectra of undegummed eri and tasar silks. The spectra shows the amide I absorption band at $1659 \mathrm{~cm}^{-1}(\mathrm{C}=\mathrm{O}$ stretching), amide II absorption band at $1540 \mathrm{~cm}^{-1}$ and $1560 \mathrm{~cm}^{-1}$ ( $\mathrm{N}-\mathrm{H}$ bending), and amide III absorption band at 1379 and $1388 \mathrm{~cm}^{-1}$ (C-N stretching) respectively for the undegummed eri and tasar silks. These absorption bands are

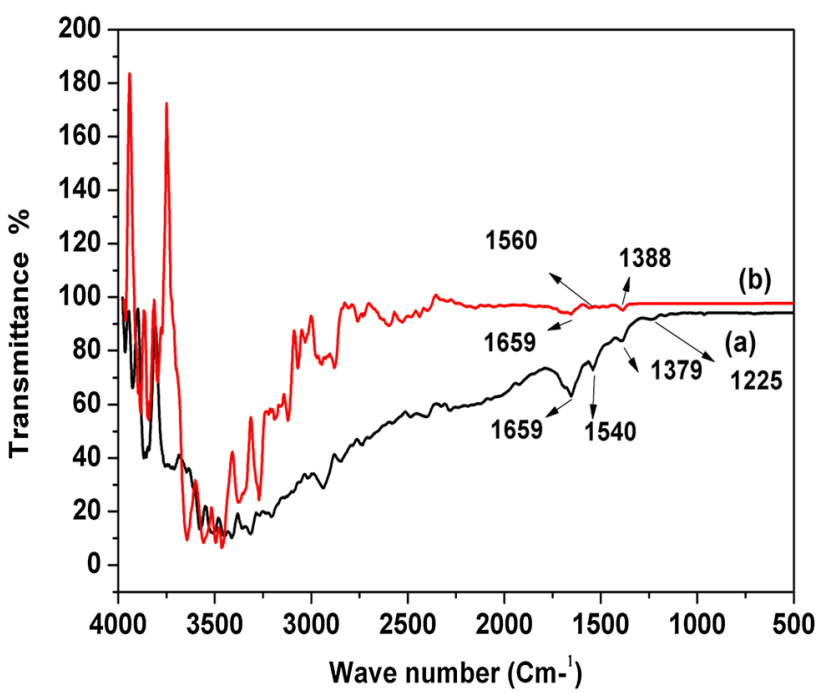

Fig. 4 FTIR spectra of undegummed $a$ eri and $b$ tasar silk filaments

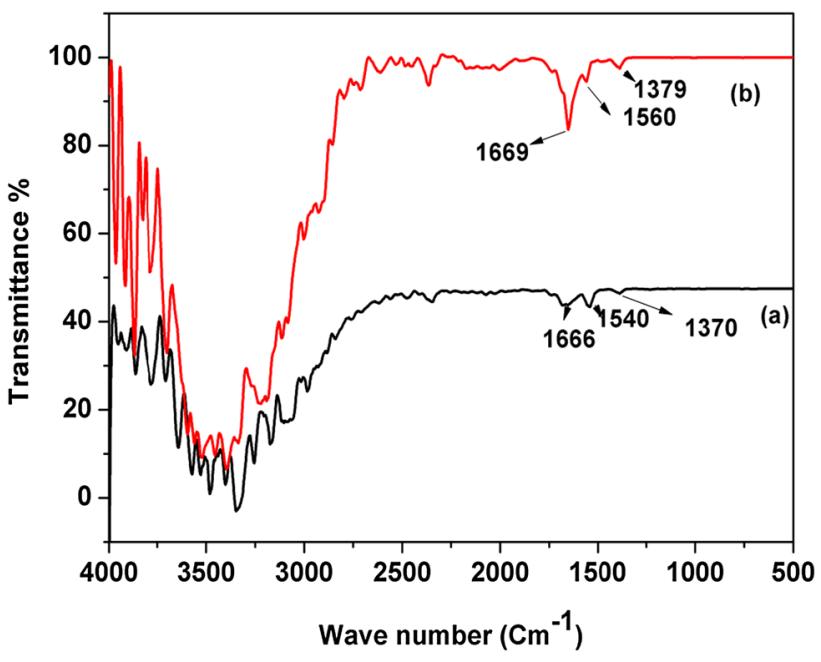

Fig. 5 FTIR spectra of degummed $a$ eri and $b$ tasar silk filaments

attributed to the $\beta$-sheet structure of the silk fibroin (Simchuer et al. 2010; Muthumanickkam et al. 2010; NasimAmiraliyan and Kish 2009).

Figure 5a, b respectively shows the FTIR spectra of degummed eri and tasar silks. The spectra shows the amide I absorption band at 1666 and $1669 \mathrm{~cm}^{-1}$, amide II absorption band at 1540 and $1560 \mathrm{~cm}^{-1}$, and amide III absorption band at 1370 and $1379 \mathrm{~cm}^{-1}$ respectively for the degummed Eri and Tasar silks. From the spectra (Figs. 4a, 5a), it could be observed that the wave number of amide I of Eri and Tasar silk has shifted from 1659 to $1666 \mathrm{~cm}^{-1}$ and 1659 to $1669 \mathrm{~cm}^{-1}$ respectively due to the degumming process. This may be attributed to the change from $\beta$-sheet structure to $\alpha$-helix structure of silk due to degumming process (Muthumanickkam et al. 2013b). 
Figures $6 \mathrm{a}, \mathrm{b}$, respectively shows the FTIR spectra of ESF and TSF scaffolds without ethanol treatment. The spectrum (6a) shows the amide I absorption band at $1673 \mathrm{~cm}^{-1}$, amide II absorption band at $1530 \mathrm{~cm}^{-1}$ and amide III absorption band at $1254 \mathrm{~cm}^{-1}$ for ethanol untreated ESF scaffold. The spectrum (6b) shows the amide I absorption band at $1630 \mathrm{~cm}^{-1}$ amide II absorption band at $1509 \mathrm{~cm}^{-1}$ and amide III absorption band at $1227 \mathrm{~cm}^{-1}$ for the ethanol untreated TSF scaffold.

Figures 7a, b, shows the FTIR spectra of ethanol treated ESF and TSF scaffolds. ESF scaffold (7a) shows the amide I absorption band at $1630 \mathrm{~cm}^{-1}$, amide II absorption band at $1509 \mathrm{~cm}^{-1}$ and amide III absorption band at $1237 \mathrm{~cm}^{-1}$. TSF scaffold (7b) showsthe amide I absorption band at $1620 \mathrm{~cm}^{-1}$, amide II absorption band at $1509 \mathrm{~cm}^{-1}$ and amide III absorption band at $1237 \mathrm{~cm}^{-1}$. The amide I absorption band has shifted from 1630 to $1620 \mathrm{~cm}^{-1}$ due to ethanol treatment of TSF scaffold, whereas the shift is from 1673 to $1630 \mathrm{~cm}^{-1}$ for the ethanol treatment of ESF

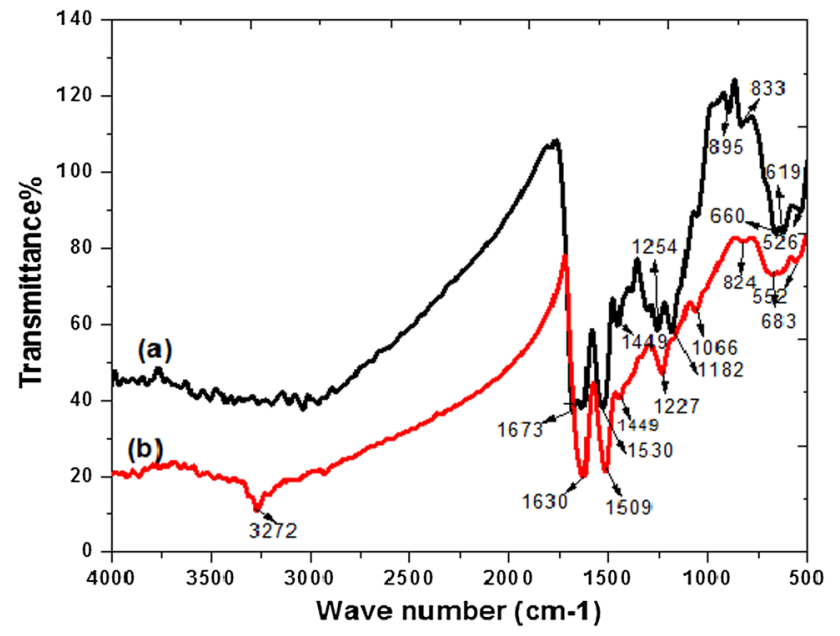

Fig. 6 FTIR spectra of ethanol untreated $a$ ESF and $b$ TSF scaffolds

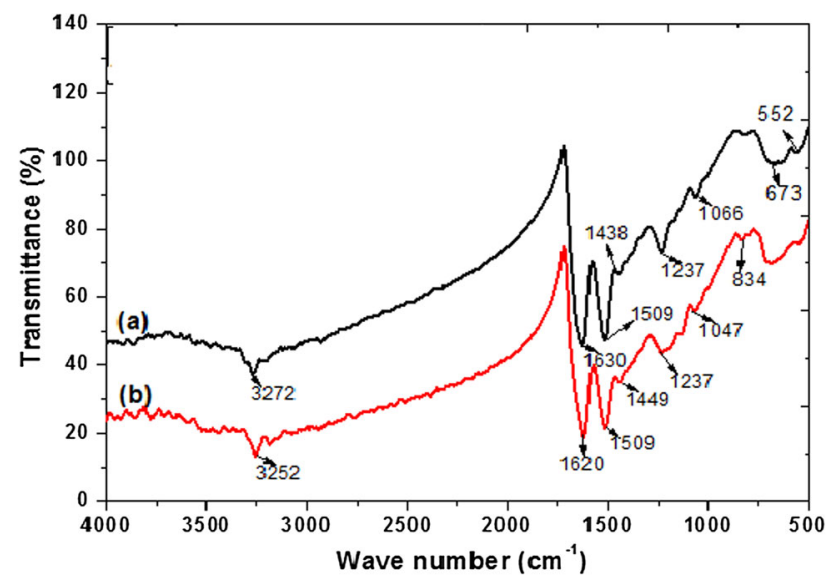

Fig. 7 FTIR spectra of ethanol treated $a$ ESF and $b$ TSF scaffolds scaffold. This shift may be due to change from $\alpha$-helix to $\beta$-structure of the silkfibroin due to ethanol treatment. The ethanol treatment causes rearrangement of the hydrogen bonds in the silk fibroin nanofibrous scaffolds.

\section{XRD analysis}

Figure $8 \mathrm{a}$, shows the diffraction peaks at $20.2^{\circ}, 16.6^{\circ}$ and $8.5^{\circ}$ for undegummed eri silk, and their corresponding spaces are $4.39 \mathrm{~A}^{\circ}, 5.34 \mathrm{~A}^{\circ}$ and $10.4 \mathrm{~A}^{\circ}$ respectively. The strong intensity peaks appearing at $20.2^{\circ}$ and $16.6^{\circ}$ may be attributed to the crystalline structure and the weak intensity peak appearing at $8.5^{\circ}$ is due to the non-crystalline structure.

Figure $8 \mathrm{~b}$, shows the diffraction peaks at $22.79^{\circ}, 11.49^{\circ}$ and $8.8^{\circ}$ for ethanol untreated ESF scaffold, and their corresponding spaces are $3.90 \mathrm{~A}^{\circ}, 7.7 \mathrm{~A}^{\circ}$ and $10.04 \mathrm{~A}^{\circ}$

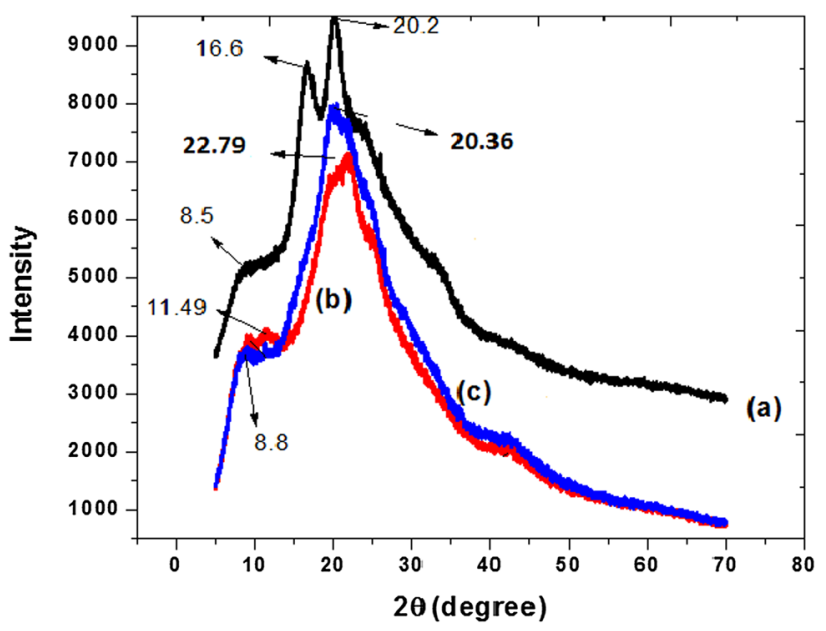

Fig. 8 XRD diffrograms of $a$ Undegummed Eri silk filament $b$ Ethanol untreated ESF scaffold and $c$ Ethanol treated ESF scaffold

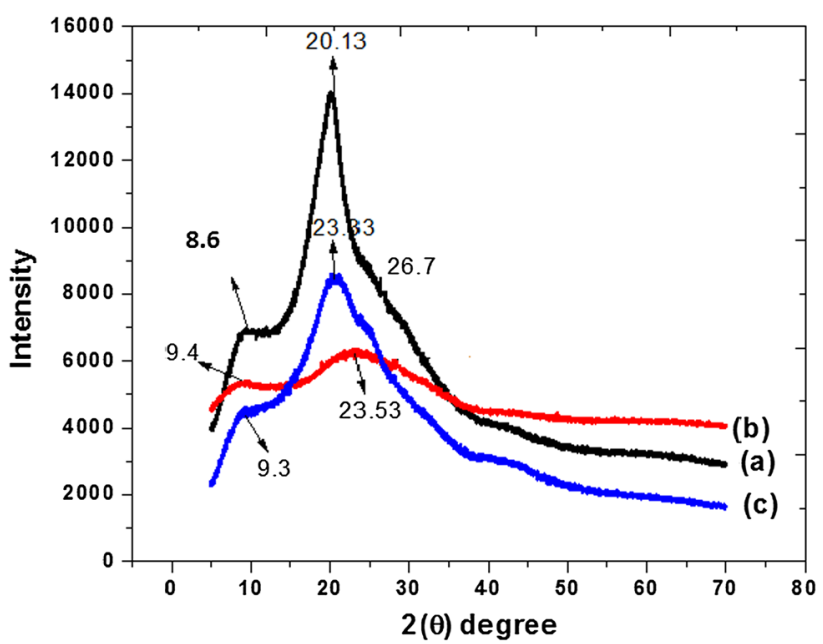

Fig. 9 XRD diffrograms of $a$ Undegummed Tasar silk filament $b$ Ethanol untreated TSF scaffold and $c$ Ethanol treated TSF scaffold 
respectively. The weak intensity peak appearing at $11.49^{\circ}$ indicates amorphous content in the untreated ESF scaffold. Figure $8 \mathrm{c}$, shows the diffraction peaks at $20.36^{\circ}$ and $8.8^{\circ}$

Table 1 Crystallinity and crystallite size of eri and tasar silks and their scaffolds

\begin{tabular}{lll}
\hline Materials & $\begin{array}{l}\text { Crystallinity } \\
(\%)\end{array}$ & $\begin{array}{l}\text { Crystallite size } \\
\left(\mathrm{A}^{\circ}\right)\end{array}$ \\
\hline Undegummed eri silk filament & 47.78 & 36.3 \\
Ethanol untreated ESF scaffold & 40.90 & 26.6 \\
Ethanol treated ESF scaffold & 46.73 & 33.3 \\
Undegummed tasar silk filament & 44.31 & 38.5 \\
Ethanol untreated TSF scaffold & 41.11 & 26.0 \\
Ethanol treated TSF scaffold & 42.77 & 38.5 \\
\hline
\end{tabular}

(a)
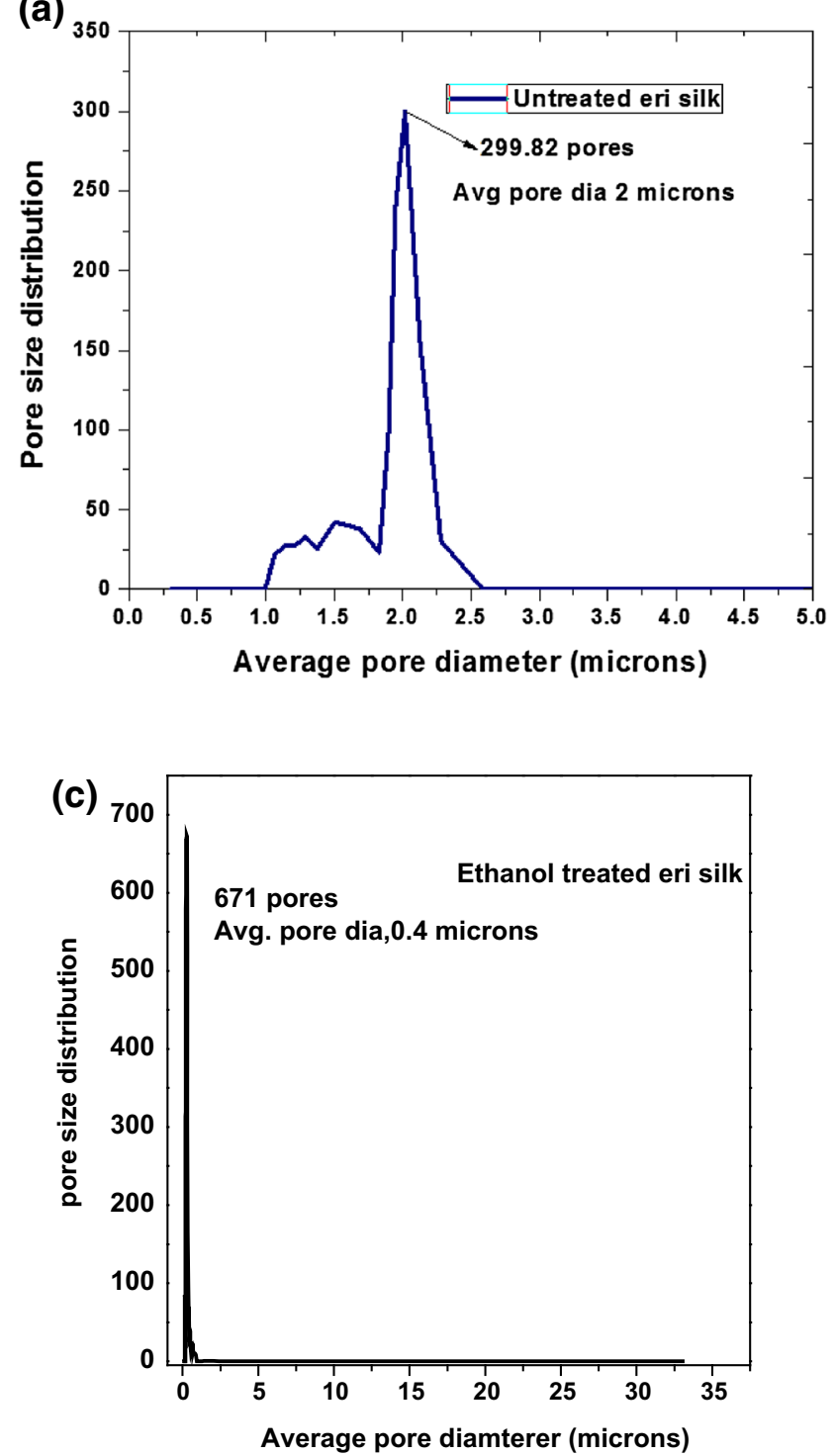

for ethanol treated ESF scaffolds and their corresponding spaces are $4.36 \mathrm{~A}^{\circ}$ and $10.04 \mathrm{~A}^{\circ}$ respectively. The intensity of the peak at $20.36^{\circ}$ (Fig. 8c) is higher than the intensity of peak at $22.79^{\circ}$ (Fig. 8b), which may be due to the conversion of part of the random coil structure to $\beta$ crystalline structure by ethanol treatment.

Figure $9 \mathrm{a}$, shows the diffraction peaks at $20.13^{\circ}$ and $8.6^{\circ}$ for undegummed tasar silk and their corresponding spaces are $4.41 \mathrm{~A}^{\circ}$ and $10.27 \mathrm{~A}^{\circ}$ respectively. The strong intensity peak at $20.13^{\circ}$ is due to the crystalline region. Figure $9 \mathrm{~b}$, shows the diffraction peaks at $23.53^{\circ}$ and $9.4^{\circ}$ for TSF scaffold without ethanol treatment and their corresponding spaces are $3.78 \mathrm{~A}^{\circ}$ and $9.4 \mathrm{~A}^{\circ}$. Figure $9 \mathrm{c}$, shows the diffraction peaks at $23.33^{\circ}$ and $9.3^{\circ}$ for ethanol treated TSF scaffold and their corresponding spaces are $3.81 \mathrm{~A}^{\circ}$ and

(b)

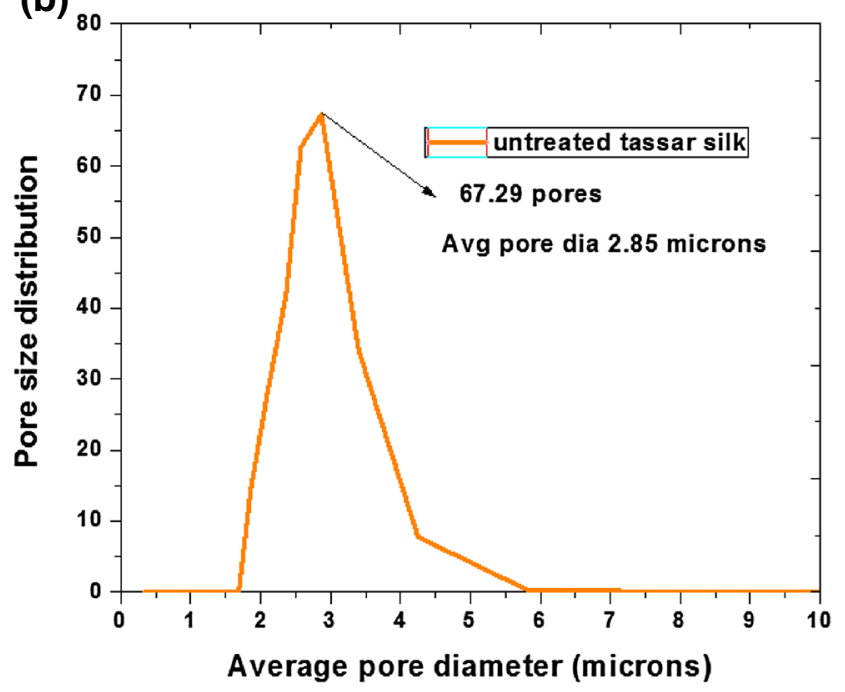

(d)

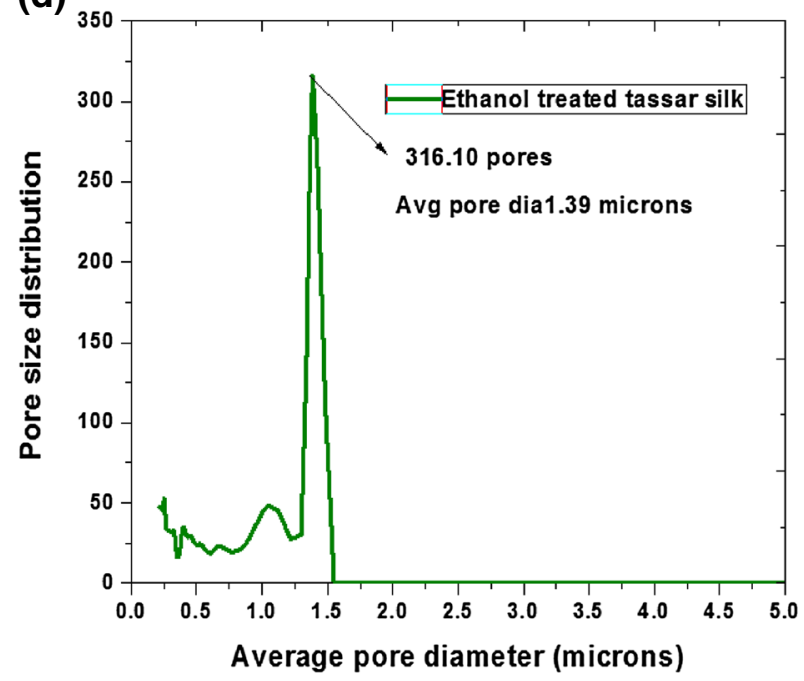

Fig. 10 Pore size distribution of a Ethanol untreated ESF, b Ethanol untreated TSF, $\mathbf{c}$ Ethanol treated ESF and d ethanol treated TSF scaffolds 
$9.5 \mathrm{~A}^{\circ}$. The intensity of the peak at $23.33^{\circ}$ (Fig. 9c) is higher than the intensity of peak at $23.53^{\circ}$ (Fig. 9b), which may be attributed to the conversion of part of the random coil structure to $\beta$-crystalline structure by ethanol treatment (Nazarov et al. 2004).

Table 1 shows the average crystal size and the crystalline percentage of eri and tasar silks, and ESF and TSF scaffolds.

Silk II structure ( $\beta$-sheet structure) is connected with crystalline region and the silk I structure (random coil) structure is connected with amorphous region. The results show that crystalline percentage is higher in ethanol treated electrospun scaffolds than the untreated scaffolds. After the ethanol treatment, silk I structure changes into silk II structure. Ethanol treated ESF scaffold shows higher crystalline percentage than the TSF scaffolds due to higher alanine content present in the eri silk.

\section{Porosity}

Figure 10a-d, shows the pore size distribution of ESF and TSF scaffolds with and without ethanol treatment. ESF scaffold without ethanol treatment in Fig. 10a shows that majority of the pores have diameter in the range of $1.5-2.3 \mu \mathrm{m}$ with the mean pore diameter of $2.0 \mu \mathrm{m}$, whereas, the TSF scaffold without ethanol treatment (Fig. 10b) shows that majority of the poreshave the diameter in the range of 2-4 $\mu \mathrm{m}$ with the mean pore diameter of $2.85 \mu \mathrm{m}$.

Figure 10c, d, shows that majority of the pores have diameter in the range of $0.1-2 \mu \mathrm{m}$ and $1.3-1.5 \mu \mathrm{m}$, with mean pore diameter of 0.4 and $1.39 \mu \mathrm{m}$ respectively for the ethanol treated ESF and TSF scaffolds. When the electrospun mat is immersed in ethanol, it swells and shrinks (Muthumanickkam et al. 2010; NasimAmiraliyan and Kish 2009). The relative shrinkage of nanofibrous scaffolds after treatment leads to decrease in pore diameter and porosity (Thompson et al. 2007). The result shows that ESF scaffold has less range of pore size distribution and has less pore diameter compared to that of TSF scaffold due to the reason that the diameter of ESF fibres are less compared to that of TSF fibres. This may help for better cell attachment and proliferation on the scaffolds.

\section{Water uptake}

Table 2 shows the water uptake of ESF and TSF scaffolds with and without ethanol treatment. The water uptake percentage of ESF scaffold is lower than that of TSF scaffold due to higher hydrophilic to hydrophobic amino acids ratio in TSF scaffolds. It can be seen from the table that the water uptake reduces due to ethanol treatment. The reduction in water uptake is due to increase in crystallinity and reduction in pore size.
Table 2 Water uptake of ESF and TSF scaffolds

\begin{tabular}{ll}
\hline Materials & Water uptake $(\%)$ \\
\hline Ethanol untreated TSF scaffold & 75.34 \\
Ethanol untreated ESF scaffold & 73.54 \\
Ethanol treated TSF scaffold & 59.48 \\
Ethanol treated ESF scaffold & 57.18 \\
\hline
\end{tabular}

\section{Tensile strength}

The mean tensile stress and strain values are $0.860 \mathrm{MPa}$, $4.87 \%$ and $0.501 \mathrm{MPa}, 3.0 \%$ for untreated eri and tasar silk fibroin scaffolds respectively. The eri silk has higher tensile stress and tensile strain than that of tasar silk fibroin scaffold. The mean tensile stress and strain values are 1.375 MPa, $2.352 \%$ and $1.414 \mathrm{MPa}, 3.7 \%$ for ethanol treated tasar and eri silk fibroin scaffolds respectively. From the results, it can be seen that the tensile strength is higher in eri scaffold than the tasar scaffold due to the presence of higher crystalline region in eri fibroin. As the result of ethanol treatment, the scaffold shrinks, which increases the fibre to fibre friction and cohesive force between the fibres in the scaffold, which in turn increases the tensile strength (Muthumanickkam et al. 2013a).

\section{Biological characterization of scaffolds}

\section{Hemolysis \%}

The hemolytic percentage should be less than $5 \%$ in order to use the material for biomedical applications. Figure 11 shows that the hemolytic percentage of ESF and TSF scaffolds is 1.3 and 7.7 respectively, which indicates that ESF has better blood compatibility and can be used as biomaterial.

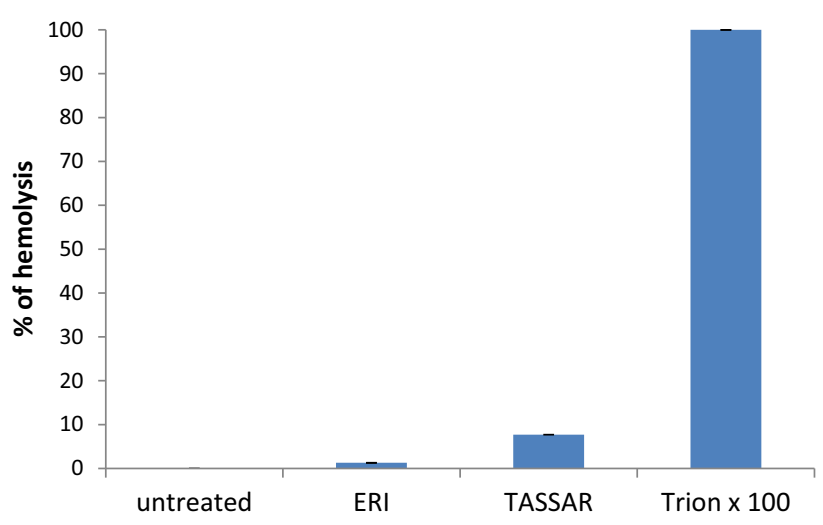

Fig. 11 Hemolytic percentages of ESF and TSF scaffolds 


\section{Platelet adhesion}

SEM images in Fig. 12a, b respectively, shows the platelet adhesion on the surface of ESF and TSF scaffolds. From the SEM images, it can be observed that ESF shows less platelet adhesion on the surface than the TSF scaffolds due to less hydrophilic ratio of eri silk (0.36) compared to that of tasar silk (0.44) (Huemmerich et al. 2006). The platelet non-adherence is important for the scaffolds to be used for biomedical applications.

\section{Cell culture}

The scaffolds are required to support cell attachment, growth, proliferation and maintain normal state of cell differentiation. To evaluate the initial cell attachment and
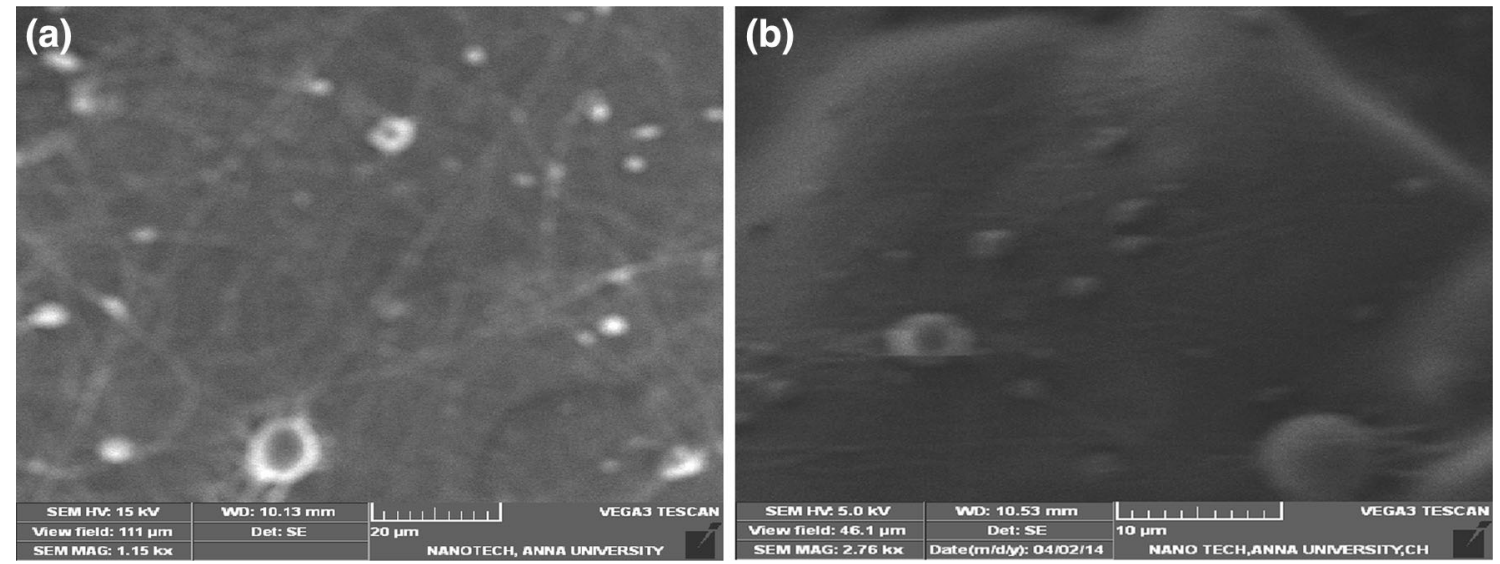

Fig. 12 Platelet adhesion on a ESF and b TSF scaffolds
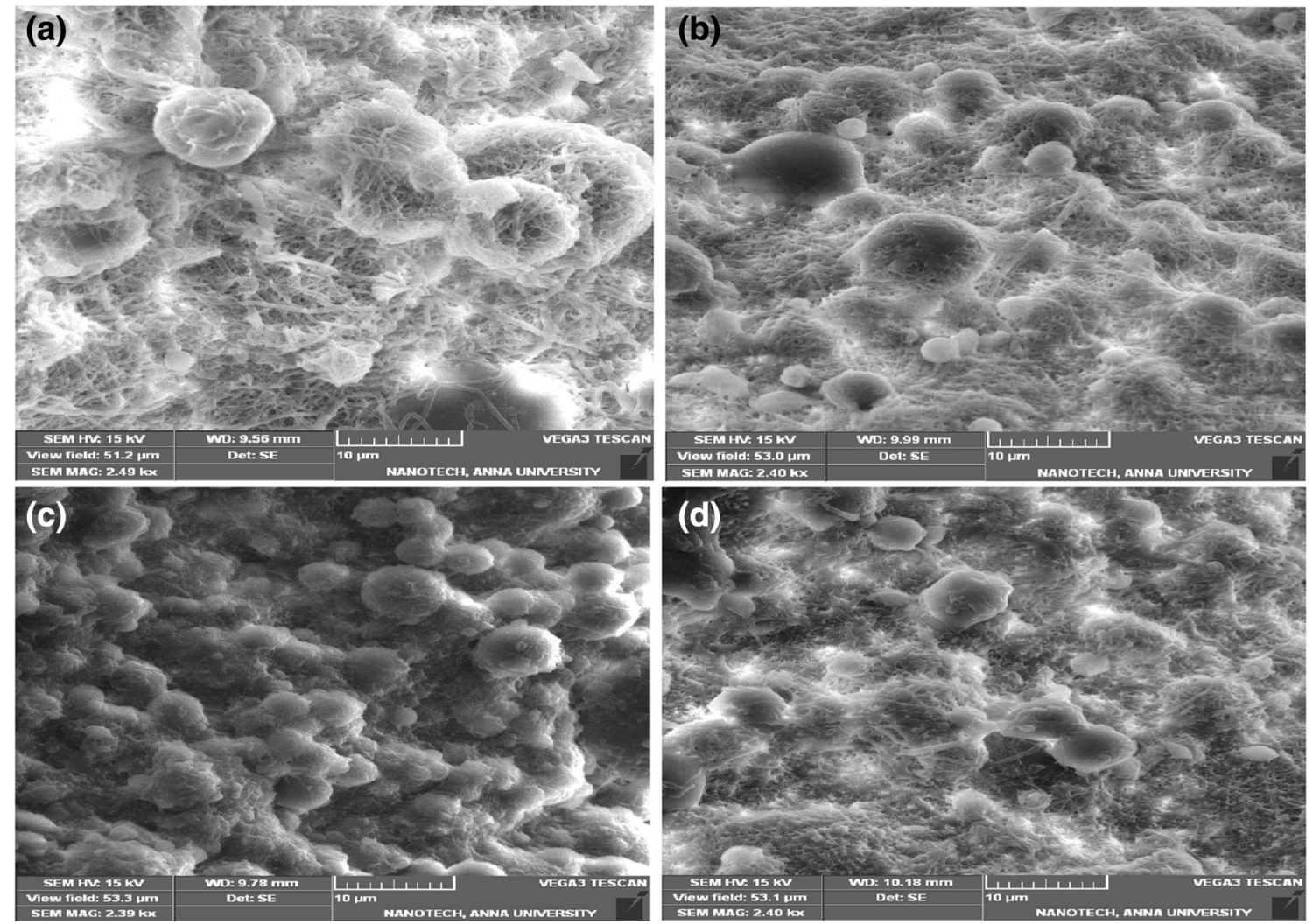

Fig. 13 Fibroblast attachment on a ESF and b TSF scaffolds after $24 \mathrm{~h}$ and $\mathbf{c}$ ESF, d TSF scaffolds after 48 


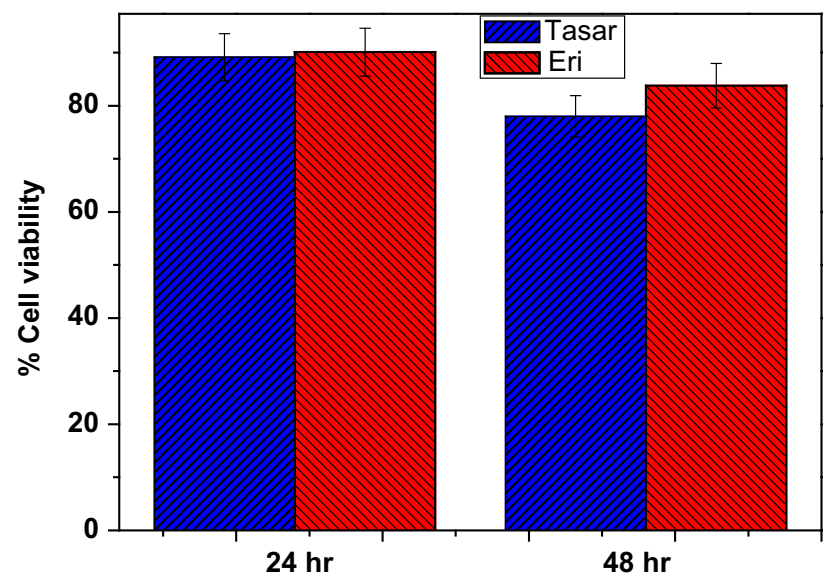

Fig. 14 Cell viability of ESF and TSF scaffolds

spreading, the fibroblast L6 cells were seeded on the ESF and TSF scaffolds.

SEM images in Fig. 13a, b, shows the fibroblast cell attachment and spreading on ESF and TSF scaffolds after $24 \mathrm{~h}$ and Fig. 14c, d, shows the cell attachment after $48 \mathrm{~h}$ on ESF and TSF scaffolds. It can be seen from the Fig. 13a, $b$ that both ESF and TSF scaffolds show better L6 fibroblast cell attachment in $24 \mathrm{~h}$ of incubation. But after $48 \mathrm{~h}$, TSF shows lesser cell attachment than the ESF. The cell attachment and spreading is higher in ESF scaffold due to higher amount of positively charged amino acids (Muthumanickkam et al. 2013a; Minoura et al. 1995; Patra and Talukdar 2012).

\section{Cell viability}

Figure 14, shows the cell viability of ESF and TSF scaffolds for the period of 24 and $48 \mathrm{~h}$ respectively. The percentage of cell viability in ESF and TSF scaffolds are 90.11 and $89.15 \%$ for $24 \mathrm{~h}$ and 83.78 and $78.01 \%$ for $48 \mathrm{~h}$.

ESF shows marginally higher cell viability percentage than TSF scaffolds, however, statistically not significant.

\section{Conclusions}

The eri silk and tasar silk scaffolds were produced by electro spinning method. The scaffolds were treated with ethanol to increase dimensional stability. Ethanol treatment increased the crystallinity percentage of both ESF and TSF scaffolds. Thermal stability of the ESF scaffold was found to be better than that of the TSF scaffold. The hemolytic percentage of TSF and ESF scaffold was found to be 7.7 and $1.3 \%$ respectively, which indicates that ESF has better blood compatibility than TSF scaffold. The platelet adhesion on the ESF scaffold was less than the TSF scaffold. The cell attachment, binding and spreading on the ESF scaffold was superior compared to the TSF scaffold. In most of the characteristics, the ESF scaffold shows better performance compared to that of TSF scaffold and hence ESF can be considered a suitable biomaterial for biomedical applications.

Acknowledgments The authors are thankful to the Council of Scientific and Industrial Research (CISR), New Delhi, India for financial support this research work (80 (0076)/II/EMR-11).

Open Access This article is distributed under the terms of the Creative Commons Attribution 4.0 International License (http://crea tivecommons.org/licenses/by/4.0/), which permits unrestricted use, distribution, and reproduction in any medium, provided you give appropriate credit to the original author(s) and the source, provide a link to the Creative Commons license, and indicate if changes were made.

\section{References}

Altman GH, Diaz F, Jakuba C, Calabro T, Horan RL, Chen J, Lu H, Richmond J, Kaplan DL (2003) Silk-based biomaterials. Biomaterials 24:401-416

Bray LJ, Suzuki S, Harkin DG, Chirila TV (2013) Incorporation of exogenous RGD peptide and inter-species blending as strategies for enhancing human corneal limbal epithelial cell growth on bombyxmori silk fibroin membranes. J Functional Biomater 4:74-88

Ho Mei-po, Wang Hao, Lau Kin-tak (2012) Effect of degumming time on silkworm silk fibre for biodegradable polymer composites. J Appl surface sci 258:3948-3955

Huemmerich D, Slotta U, Scheibel T (2006) Films from recombinant spider silk proteins. Appl Phys A 82:219-222

Meinel L, Hofmann S, Karageorgiou V, Kirker-Head C, McCool J, Gronowicz G, Zichner L, Langer R, Vunjak-Novakovic G, Kaplan DL (2003) The inflammatory responses to silk films in vitro and in vivo. Biomaterials 26:147-155

Min B, Lee G, Kim SH, Nam YS, Lee TS, Park WH (2004) Electrospinning of silk fibroin nanofibers and its effect on the adhesion and spreading of normal human keratinocytes and fibroblasts in vitro. Biomaterials 25:1289-1297

Minoura N, Aiba S, Higuchi M, Gotoh Y, Tsukada M, Imai Y (1995) Attachment and growth of fibroblast cells on silk fibroin. Biochim Biophys Res Commun 208:511-516

Muthumanickkam A, Elankavi E, Gayathri R, KuberaSampathkumar S, Vijayakumar G, Muthukumar K, Subramanian S (2010) Tensile and in vitro degradation study of electro spun fibrous mat produced from eri silk fibroin. Int J Mater Res 12:1548-1553

Muthumanickkam A, Subramanian S, Prasanna V, Natarajan TS, Ramashanker V (2013a) Characterization of electrospun fibrous scaffold produced from Indian eri silk fibroin. Int J Mater Res 104:498-506

Muthumanickkam A, Subramanian S, Goweri M, Ganesh V, SofiBeaula W (2013b) Comparative study on eri silk and mulberry silk fibroin scaffolds for biomedical applications. Iran Poly J 22:143-154

Nakazawa Y, Bamba M, Nishio S, Asakura T (2003) Tightly winding structure of sequential model peptide for repeated helical region in Samiacynthia ricini silk fibroin studied with solid-state NMR. Protein Sci 12:666-671

NasimAmiraliyan Mahdi Nouri, Kish Mohammad Haghighat (2009) Electrospinning of Silk Nanofibers I. An investigation of 
nanofiber morphology and process optimization using response surface methodology. Fibres Polymers 10:167-176

Nazarov R, Jin HJ, Kaplan DL (2004) Porous 3-D scaffolds from regenerated silk fibroin. Biomacromolecules 5:718-726

Patra C, Talukdar S, Novoyatleva T, Velagala S, Mühlfeld C, Kundu B, Kundu SC, Engel FB (2012) Silk protein fibroin from Antheraeamylitta for cardiac tissue engineering. Biomaterials 33:2673-2680

Santin M, Motta A, Freddi G, Cannas M (1999) In vitro evaluation of the inflammatory potential of the silk fibroin. J Biomed Mater Res 46:382-389

Sen Kushal, MurugeshBabu K (2003) Studies on Indian silk. II Structure-property correlations. J Appl Polym Sci 92:1098-1115
Sen Kushal, MurugeshBabu K (2004) Studies on Indian silk I macrocharacterization and analysis of amino acid composition. J Appl Polym Sci 92:1080-1097

Simchuer W, Phromnut N, Intarasorn S, Srihanam P (2010) The properties of eri (Samiaricini) silk fibroin fibers: effect of different organic solvents. Int J Appl Chem 6:373-382

Thompson CJ, Chase GG, Yarin AL, Reneker DH (2007) Effects of parameters on nanofiber diameter determined from electrospinning model. Polymer 48:6913-6922

Zhang Kui-Hua, Ye Qing, Yan Zhi-Yong (2012) Influence of posttreatment with $75 \%(\mathrm{v} / \mathrm{v})$ ethanol vapor on the properties of $\mathrm{SF} /$ P (LLA-CL) nanofibrous scaffolds. Int J Mol Sci 13:2036-2047 